\title{
PENGEMBANGAN GAME PUZZLE BERBASIS CONSTRUCT 2 SEBAGAI MEDIA PEMBELAJARAN SISTEM PEREDARAN DARAH KELAS XI DI SMA NEGERI 1 SELAYAR
}

\author{
Sitti hardiyanti ${ }^{1}$, Muh. Khalifah Mustami ${ }^{2}$, Andi Mu'nisa ${ }^{3}$ \\ ${ }^{1}$ Program Studi Pendidikan Biologi Universitas Negeri Makassar \\ ${ }^{2}$ Universitas Islam Negeri Makassar, Makassar \\ ${ }^{3}$ Universitas Negeri Makassar, Makassar \\ sittihardiyanti72@gmail.com
}

\begin{abstract}
ABSTRAK
Jenis penelitian ini adalah penelitian dan pengembangan (Reseach and Development) yang bertujuan untuk mengembangkan game puzzle berbasis construct 2 sebagai media pembelajaran sistem peredaran darah yang valid dan praktis serta efektif yang dapat meningkatkan minat, motivasi dan hasil belajar peserta didik. Penelitian ini menggunakan model pengembangan 4D (define, design, develop and disseminate). Jenis data yang dikumpulkan dari penelitian dan pengembangan ini yaitu data penilaian dan masukan ahli materi dan ahli media mengenai proses pengembangan media pembelajaran, data tanggapan guru dan peserta didik terhadap game puzzle berbasis construct 2, data tentang keterlaksanaan kegiatan pembelajaran, data tentang minat belajar, motivasi belajar dan hasil belajar peserta didik. Data yang diperoleh selanjutnya dianalisis secara kuantitatif. Hasil pengembangan game puzzle berbasis construct 2 memiliki karakteristik dapat meningkatkan minat, motivasi dan hasil belajar peserta didik. Minat belajar peserta didik sebelum menerapkan game puzzle berbasis construct 2 berada dalam kategori cukup dengan persentase 58,82\% dan setelah diterapkan game puzzle berbasis construct 2 minat belajar belajar peserta didik meningkat menjadi 61,76\% kategori baik. Motivasi belajar peserta didik sebelum menerapkan game puzzle berbasis construct 2 berada pada kategori cukup dengan persentase $61,76 \%$ dan setelah diterapkan game puzzle berbasis construct 2 motivasi belajar peserta didik meningkatkan menjadi $100 \%$ yang berada dalam kategori sangat baik. Hasil belajar peserta didik sebelum menerapkan game puzzle berbasis construct 2 yaitu terdapat $85 \%$ peserta didik yang mencapai KKM 75 dan setelah menerapkan game puzzle berbasis construtc 2 terdapat $88 \%$ peserta didik yang mencapai KKM 75. Game puzzle berbasis construct 2 layak digunakan dalam proses pembelajaran karena tergolong dalam kategori valid baik dari penilaian media dan materi. Game puzzle berbasis construct 2 praktis digunakan dalam proses pembelajaran terbukti dengan diberikannya respon positif dari guru dan peserta didik. Penelitian ini menghasilkan perangkat pembelajaran dengan sumber belajar berupa game puzzle berbasis construct 2 sebagai media pembelajaran sistem peredaran darah di SMA Negeri 1 Selayar.

Kata Kunci: Game Puzzle, Construct 2, Media Pembelajaran, Sistem Peredaran Darah.
\end{abstract}

\begin{abstract}
The study is research and development, which aims at developing puzzle game based on construct 2 as learning media of bloodstream system which is valid, practical, and effective to improve interest, motivation, and learning outcomes. The study employed 4D development model (defining, design, development, and dissemination). The type of data collection of the study were data of assessment and feedback from the material expert and media expert on development process of learning media, data of implementation of learning activity, data of learning interest, learning motivation, and learning outcomes. The result of puzzle game development based on construct 2 has characteristics able to improve the interest, motivation, and learning outcomes. The learning interest of students before applying puzzle game based on construct 2 is in medium category with 58,82\% and after applying puzzle game based on construct 2 the learning interest of students is improve to 61,76\% which is in good category. The learning motivation of students before applying puzzle game based on construct 2 is in medium category with $61,76 \%$ and after applying puzzle game based on construct 2 the learning motivation of students improves to $100 \%$ which is in very good category. The learning outcomes after applying puzzle game based on construct $288 \%$ of the students achieve the KKM of 75. The puzzle game based on construct 2 is feasible to assessment of the media and material. The puzzle game based on construct 2 is practical to be applied in learning process proven by the positive response obtained from the teacher and students. This study prodeces the learning tools with puzzle game learning source based on construct 2 as the learning media of bloodstream system at SMAN 1 Selayar.
\end{abstract}

Keywords: Puzzle Game, Construct 2, Learning Media, Circulatory System. 


\section{Pendahuluan}

Pada hakikatnya proses belajar mengajar adalah proses komunikasi. Komunikasi terjadi karena adanya interaksi antara guru dengan peserta didik, interaksi antar peserta didik, yang memberikan dampak besar dalam jalannya proses pembelajaran (Liu \& Chen, 2013). Kondisi belajar mengajar yang efektif adalah adanya minat dan motivasi peserta didik dalam belajar. Minat merupakan suatu sifat yang relatif menetap pada diri seseorang. Sedangkan motivasi merupakan suatu daya atau kekuatan yang timbul dari dalam diri peserta didik untuk memberikan kesiapan agar tujuan yang telah ditetapkan tercapai (Usman, 2013).

Masalah yang sering dialami oleh guru sekarang ini adalah kurangnya minat dan motivasi peserta didik dalam belajar maupun menerima materi pelajaran di dalam kelas, yang akhirnya mempengaruhi hasil belajar peserta didik. Rendahnya hasil belajar peserta didik juga disebabkan karena kesulitan memahami materi yang terlampau banyak dan sumber belajar yang terbatas (Yudasmara \& Purnami, 2015). Kebanyakan pembelajaran di sekolah masih menggunakan metode pengajaran yang berpusat pada guru atau teacher centered dengan menggunakan buku sebagai media pembelajaran atau sistem pembelajaran manual (Daud \& Rahmadana, 2015).

Sistem pembelajaran manual membuat peserta didik jenuh dan akhirnya terhambat dalam belajar. Pembelajaran manual yang menjemukan bagi peserta didik sudah lama berlangsung di sekolah. Karena pembelajaran manual, peserta didik lambat untuk memahami materi yang ada (Gunawan, 2015). Berdasarkan hasil observasi yang telah dilakukan di SMA Negeri 1 Selayar menunjukkan bahwa kebanyakan guru menggunakan metode ceramah dan model pembelajaran yang umum dilakukan adalah model pembelajaran active learning tipe quiz team.

Kekurangan metode ceramah yaitu metode ceramah dirasa kurang melekat pada ingatan peserta didik, membosankan dan juga menoton (Hisyam, 2008). Sedangkan pada model pembelajaran active learning tipe quiz team terkadang membuat konsentrasi peserta didik terpecah dengan hal lain karena peserta didik kebanyakan hanya bermain dengan teman kelompoknya, akibatnya peserta didik kurang memahami materi pelajaran. Selain itu, tidak sedikit peserta didik yang merasa bosan, tidak mempunyai minat belajar, motivasi kurang, yang akhirnya mempengaruhi hasil belajar peserta didik. Faktor yang diduga menjadi penyebab permasalahan ini adalah media mengajar yang kurang variatif dan sajian materi pada buku ajar yang kurang menarik.

Peserta didik menganggap Biologi itu sulit dimengerti karena banyaknya hafalan dari buku teks dan tidak adanya visualisasi yang cukup untuk setiap bahasan materi ajar (Yudasmara \& Desi, 2015). Salah satunya pada materi sistem peredaran darah. Materi sistem peredaran darah merupakan salah satu materi yang dianggap sulit dimengerti oleh peserta didik di SMA Negeri 3 Selayar. Sebagaimana yang kita ketahui bahwa materi sistem peredaran darah merupakan materi yang membutuhkan media pembelajaran visual, baik itu berupa video ataupun gambar. Maka dari itu, penggunaan media dalam proses belajar mengajar sangat dibutuhkan untuk menarik perhatian peserta didik dan menciptakan kegiatan belajar yang menyenangkan dan efektif (Annisa \& Marlina, 2014).

Salah satu upaya untuk meningkatkan keberhasilan belajar peserta didik dengan menjadikan game sebagai media pembelajaran. Game merupakan hal yang tidak bisa dipisahkan dari perkembangan seorang anak (Kurniawan, Tambunan, \& Sardi, 2015). Kunci utama mengapa game berpotensi sebagai media pembelajaran yang efektif adalah karena motivasi untuk bermain game bagi kalangan pembelajar sangat besar (Braghirolli, et al, 2016). Game dapat mempengaruhi fungsi kognitif dan motivasi peserta didik serta merangsang keingintahuan peserta didik, terlebih lagi apabila memasukkan tantangan dan unsur fantasi ke dalam sebuah game (Amory \& Seagram, 2003).

Game yang cocok diterapkan pada peserta didik adalah game puzzle berbasis construct 2 yang digunakan sebagai media pembelajaran. Puzzle adalah sejenis permainan yang berupa potongan-potongan gambar yang cara bermainnya yaitu dengan menyusunnya sehingga terbentuk sebuah gambar, dengan tujuan untuk melatih kesabaran, memudahkan peserta didik dalam memahami konsep, memecahkan masalah, saling bekerja sama dengan teman, serta mengembangkan keterampilan motorik dan kognitif peserta didik (Husna, Sari, \& Halim, 2017).

Penelitian yang dilakukan oleh Lutviani (2016) menyatakan bahwa pengembangan puzzle sebagai media pembelajaran pada materi indonesia masa islam dapat meningkatkan aspek kognitif, afektif, maupun psikomotor peserta didik. Berdasarkan pertimbangan tersebut, maka peneliti termotivasi mengambil judul penelitian tentang "Pengembangan Game Puzzle Berbasis Construct 2 sebagai Media Pembelajaran Sistem Peredaran darah di SMA Negeri 1 Selayar". Rumusan masalah dari penelitian ini yaitu 1) Bagaimana proses pengembangan game puzzle berbasis construct 2 sebagai media pembelajaran sistem peredaran darah. 2) Bagaimana pengembangan game puzzle berbasis construct 2 sebagai media pembelajaran sistem peredaran darah dapat bersifat valid. 3) Bagaimana pengembangan game puzzle berbasis construct 2 sebagai media pembelajaran sistem peredaran darah dapat bersifat praktis. 4) Bagaimana pengembangan game puzzle berbasis construct 2 sebagai media pembelajaran sistem peredaran darah dapat bersifat efektif.

\section{Metode Penelitian}

Jenis penelitian yang digunakan adalah penelitian dan pengembangan atau Research and Development (R\&D). Model pengembangan yang digunakan adalah 
model pengembangan 4D yang terdiri dari empat tahap yaitu define, design, develop dan disseminate.

Instrumen penelitian yang digunakan yaitu (1) lembar validasi media game puzzle berbasis construct 2; (2) lembar validasi materi sistem peredaran darah; (3) angket respon guru dan peserta didik terhadap media pembelajaran; (4) lembar observasi keterlaksanaan media pembelajaran; (5) angket minat belajar peserta didik; (6) angkat motivasi belajar peserta didik; (7) tes hasil belajar peserta didik.

Data diperoleh dengan menggunakan instrumen yang dikembangkan oleh peneliti, selanjutnya dianalisis secara kuantitatif dengan menggunakan rumus sebagai berikut.

\begin{tabular}{|c|c|c|}
\hline No & Nilai & Kategori \\
\hline 1 & $1 \leq \mathrm{Va}<2$ & Tidak valid \\
\hline 2 & $2 \leq \mathrm{Va}<3$ & Kurang Valid \\
\hline 3 & $3 \leq \mathrm{Va}<4$ & Cukup Valid \\
\hline 4 & $4 \leq \mathrm{Va}<5$ & Valid \\
\hline 5 & $\mathrm{Va}=5$ & Sangat Valid \\
\hline
\end{tabular}

Tabel 2 Kriteria Respon Guru (Riduwan, 2010)

\begin{tabular}{cc}
\hline Interval Skor & Keterangan \\
\hline $1 \leq \mathrm{PR}<2$ & Tidak Praktis \\
$2 \leq \mathrm{PR}<3$ & Kurang Praktis \\
$3 \leq \mathrm{PR}<4$ & Cukup Praktis \\
$4 \leq \mathrm{PR}<5$ & Praktis \\
\hline
\end{tabular}

Tabel 3 Kriteria Respon Peserta Didik (Riduwan, 2010)

\begin{tabular}{cc}
\hline Interval Skor & Keterangan \\
\hline $1 \leq \mathrm{PR}<2$ & Tidak Praktis \\
$2 \leq \mathrm{PR}<3$ & Kurang Praktis \\
$3 \leq \mathrm{PR}<4$ & Cukup Praktis \\
$4 \leq \mathrm{PR}<5$ & Praktis \\
$\mathrm{PR}=5$ & Sangat Praktis \\
\hline
\end{tabular}

Tabel 4. Kriteria Penilaian Keterlaksanaan Pembelajaran (Sudjana, 2005)

\begin{tabular}{cc}
\hline Persentase & Kategori \\
Keterlaksanaan & \\
\hline$\overline{\boldsymbol{k}}<60$ & Sangat Kurang \\
$60 \leq \boldsymbol{k} \leq 70$ & Kurang \\
$70 \leq \boldsymbol{k} \leq 80$ & Cukup \\
$80 \leq \square \leq 90$ & Baik \\
$\square \geq 90$ & Sangat Baik \\
\hline
\end{tabular}

\subsubsection{Analisis Data Keefektifan}

Tabel 5. Pengkategorian Nilai Minat dan Motivasi Belajar Peserta Didik (Sugiyono, 2010)

\begin{tabular}{|c|c|c|}
\hline No. & Nilai & Kategori \\
\hline 1. & $26-45$ & Sangat Rendah \\
\hline 2. & $46-65$ & Rendah \\
\hline 3. & $66-85$ & Cukup \\
\hline
\end{tabular}

\begin{tabular}{|c|c|c|}
\hline 4. & $86-105$ & Tinggi \\
\hline 5. & $106-125$ & Sangat Tinggi \\
\hline
\end{tabular}

Tabel 6. Tabel Persentase Minat dan Motivasi Belajar Peserta Didik

\begin{tabular}{cc}
\hline $\begin{array}{c}\text { Persentase Minat } \\
\text { Peserta Didik }\end{array}$ & Kategori \\
\hline $0 \%-20 \%$ & Sangat Kurang \\
$21 \%-40 \%$ & Kurang \\
$41 \%-60 \%$ & Cukup \\
$61 \%-80 \%$ & Baik \\
$81 \%-100 \%$ & Sangat Baik \\
\hline \multicolumn{2}{c}{ Nilai hasil belajar } \\
$\frac{\text { jumlah skor benar }}{\text { Jumlah skor maksimal }}$ x 100
\end{tabular}

mencapai KKM

Menghitung persentase jumlah siswa yang

$$
\% \mathrm{~K}=\frac{F}{n} \times 100
$$

$$
\begin{aligned}
& \text { Keterangan : } \\
& \begin{array}{ll}
\% \mathrm{~K} & =\text { Persentase siswa yang lulus } \\
F & =\text { frekuensi siswa yang lulus } \\
n & =\text { banyaknya siswa }
\end{array}
\end{aligned}
$$

\section{Pembahasan}

Game puzzle berbasis construct 2 sebagai media pembelajaran sistem peredaran darah dikembangkan dengan model 4D (define, design, develop dan disseminate).

\subsubsection{Define (pendefenisian)}

Pada analisis masalah, diketahui bahwa sebagian besar pembelajaran berlangsung dengan menggunakan metode ceramah, diskusi, dan kerja kelompok. Selain itu, media pembelajaran yang umum digunakan adalah buku dan alat peraga (torso) digunakan dalam pembelajaran biologi yang membutuhkan suatu media. Sehingga membutuhkan banyak waktu dan pembelajaran tidak sampai pada tujuan yang diharapkan.

Pada analisis karakteristik peserta didik diketahui bahwa nilai biologi peseta didik di SMA Negeri 1 Selayar sudah cukup baik namun ada beberapa peserta didik yang mengalami kesulitas untuk memahami materi yang disampaikan,halini dikarenakan adanya perbadaan kemampuan antar peserta didik yang satu dengan yang lain.

Pada analisis materi, digunakan kurikulum 2013 dengan Kompetensi dasar dan Indikator untuk SMA Kelas XI semester 1 pada materi sistem peredaran darah.

KD 3.6 = Menganalisis hubungan antara struktur jaringan penyususn organ pada system sirkulasi dalam kaitannya dengan bioproses dan gangguan fungsi yang dapat terjadi pada sistem sirkulasi manusia. Indikator: 
1. Mengidentifikasi jenis-jenis jaringan pada sistem peredaran darah.

2. Menjelaskan struktur dan fungsi jaringan pada sistem peredaran darah

3. Menghubungkan fungsi jaringan dengan sistem peredaran darah manusia

4. Mengidentifikasi bagian-bagian darah

5. Menjelaskan fungsi darah

6. Menjelaskan kandungan plasma darah

7. Membedakan sel-sel darah

8. Menjelaskan sistem penggolongan darah

9. Menjelaskan proses pembekuan darah

10. Mengidentifikasi bagian jantung manusia

11. Menganalisis mekanisme kerja alat-alat peredaran darah

12. Menjelaskan proses peredaran darah.

13. Menjelaskan proses peredaran limfa.

14. Memberikan contoh-contoh penyakit yang menyebabkan kelainan atau penyakit pada sistem peredaran darah, serta penyebab dan pencegahannya.

15.Menjelaskan teknologi-teknologi yang berhubungan dengan sistem peredaran darah.

Tahap selanjutnya adalah membuat perancangan media pembelaaran yang terdiri dari menyusun storyboard, membuat rancangan tampilan, perbaikan sesuai saran dari ahli media dan ahli materi sebelum akhirnya diuji cobakan di dalam kelas. Sedangkan storyboard digunakan untuk memudahkan dalam menentukan tampilan yang akan dibuat dalam media pembelajaran, sehingga dapat mempermudah pengembang uttuk menentukan bahan-bahan yang harus dilengkapi.

Rancangan tampilan game puzzle sebagai media pembelajaran terdiri atas: 1) intro dan petunjuk penggunaan; 2) menu utama yang terdiri dari $\mathrm{KD}$, indikator, materi, latihan soal, dan game puzzle; 3) navigasi exit.

Media pembelajaran yang akan dikembangkan menggunakan program construct 2. Software yang digunakan adalah construct 2 , android studio dan nox player.

Setelah game puzzle berbasis construct 2 dikembangkan maka dilakukan validasi media dan materi yang dilakukan oleh para ahli.

Tahap ini dilakukan agar produk dapat dimanfaatkan oleh orang lain. Di tahap ini media yang telah diuji kevalidan, kepraktisan, dan keefektifannya kemudian akan disosialiasikan melalui pendistribusian dalam jumlah terbatas kepada guru biologi SMA Negeri 3 Selayar dan SMA Negeri 1 Selayar.

Tabel 7. Hasil Analisis Kevalidan Game puzzle Berbasis Construct 2

\begin{tabular}{|l|l|c|c|c|c|}
\hline No & \multirow{2}{*}{$\begin{array}{c}\text { Aspek } \\
\text { Penilaian }\end{array}$} & \multicolumn{2}{|c|}{$\begin{array}{c}\text { Rata-rata } \\
\text { Skor }\end{array}$} & Va & Ket \\
\cline { 3 - 4 } & Va1 & Va2 & & \\
\hline 1. & Penggunaan & 4,2 & 4,2 & 4,2 & Valid \\
\hline 2. & $\begin{array}{l}\text { Sistem } \\
\text { navigasi }\end{array}$ & 4 & 4 & 4 & Valid \\
\hline
\end{tabular}

\begin{tabular}{|l|l|c|c|c|c|}
\hline 3. & $\begin{array}{l}\text { Desain } \\
\text { grafis }\end{array}$ & 4 & 4 & 4 & Valid \\
\hline 4. & Isi & 3,5 & 3,5 & 3,5 & $\begin{array}{c}\text { Cukup } \\
\text { Valid }\end{array}$ \\
\hline 5. & $\begin{array}{l}\text { Fungsi } \\
\text { Jumlah }\end{array}$ & 4 & 4 & $\begin{array}{c}4 \\
4\end{array}$ & $\begin{array}{c}\text { Valid } \\
\text { Valid }\end{array}$ \\
\hline
\end{tabular}

Tabel 8. Hasil Analisis Kevalidan Materi Pembelajaran Konsep Sistem Peredaran Darah

\begin{tabular}{|l|l|c|c|c|c|}
\hline No & \multicolumn{1}{|c|}{$\begin{array}{c}\text { Aspek } \\
\text { Penilaian }\end{array}$} & \multicolumn{2}{|c|}{$\begin{array}{c}\text { Rata-rata } \\
\text { Skor }\end{array}$} & Va & Ket \\
\cline { 3 - 4 } & & Va1 & Va2 & & \\
\hline 1. & Kelayakan & 4 & 4 & 4 & Valid \\
\hline 2. & $\begin{array}{l}\text { Kelayakan } \\
\text { penyajian }\end{array}$ & 4 & 4 & 4 & Valid \\
\hline 3. & $\begin{array}{l}\text { Penilaian } \\
\text { bahasa } \\
\text { Jumlah }\end{array}$ & 4 & 4 & 4 & $\begin{array}{c}\text { Valid } \\
\text { Valid }\end{array}$ \\
\hline
\end{tabular}

Berdasarkan hasil penilaian kevalidan game puzzle berbasis construct 2 oleh dua orang validator ahli, dapat dikatakan bahwa game puzzle berbasis construct 2 yang dikembangkan telah mencapai kategori "valid", dapat dilihat perolehan nilai rata-rata kedua validator yaitu $4(4 \leq \mathrm{Va}<5)$. Berdasarkan kriteria yang diperoleh, maka dapat dikatakan bahwa game puzzle berbasis construct 2 telah mencapai kevalidan dan layak digunakan dalam proses pembelajaran.

Tabel 9. Hasil Analisis Respon Guru terhadap game puzzle berbasis construct 2

\begin{tabular}{|c|l|c|c|}
\hline No. & \multicolumn{1}{|c|}{ Aspek } & Rata-rata Skor & Ket \\
\hline 1. & $\begin{array}{l}\text { Aspek } \\
\text { mengakses }\end{array}$ & 4,3 & Praktis \\
\hline 2. & Materi & 4 & Praktis \\
\hline 3. & Bahasa & 4 & Praktis \\
\hline \multicolumn{2}{|c|}{ Rata-rata } & 4,1 & Praktis \\
\hline
\end{tabular}

Tabel 10. Hasil Analisis Respon Peserta Didik terhadap Game Puzzle Berbasis Construct 2

\begin{tabular}{|l|l|c|c|}
\hline No & \multicolumn{1}{|c|}{ Aspek } & $\begin{array}{c}\text { Rata-rata } \\
\text { Skor }\end{array}$ & Ket \\
\hline 1. & $\begin{array}{l}\text { Kualitas isi dan } \\
\text { tujuan }\end{array}$ & 4,24 & Praktis \\
\hline 2. & $\begin{array}{l}\text { Kualitas daya tarik } \\
\text { dalam belajar }\end{array}$ & 4,3 & Praktis \\
\hline 3. & $\begin{array}{l}\text { Keterlibatan peserta } \\
\text { didik }\end{array}$ & 4,3 & Praktis \\
\hline \multicolumn{2}{|l|}{ Rata-rata skor } & 4,28 & Praktis \\
\hline
\end{tabular}

Berdasarkan hasil analisis di atas, dapat dilihat bahwa guru biologi memberikan respon positif terhadap media pembelajaran yang telah dikembangkan. Rata-rata nilai yang diperoleh yaitu sebesar "4,1", yang berada pada kategori "praktis". Berdasarkan hasil analisis data respon peserta didik 
terhadap game puzzle berbasis construct 2, diperoleh nilai rata-rata sebesar 4,28 yang berada pada kategori "praktis" ( $4 \leq \mathrm{PR}<5)$. Hal ini menunjukkan bahwa peserta didik memberikan respon positif terhadap game puzzle berbasis construct 2 yang dikembangkan.

Tabel 11. Distribusi Frekuensi dan Kategori Nilai Minat Belajar Peserta Didik

pembelajaran karena motivasi belajar peserta didik berada dalam kategori "sangat baik" dengan persentase " $100 \%$ " $(81 \%-100 \%)$.

Tabel 13. Analisis Skor Hasil Belajar Peserta Didik Setelah Menerapkan Game puzzle Berbasis Construct 2

\begin{tabular}{|c|l|c|}
\hline No. & \multicolumn{1}{|c|}{ Variabel } & Nilai \\
\hline 1. & Jumlah Peserta Didik & 34 \\
\hline 2. & Rata-rata & 81,79 \\
\hline 3. & Skor Maksimum & 93 \\
\hline 4. & Skor Minimum & 72 \\
\hline 5. & $\begin{array}{l}\text { Jumlah Peserta Didik yang } \\
\text { lulus }\end{array}$ & 30 \\
\hline 6. & $\begin{array}{l}\text { Jumlah peserta didik yang } \\
\text { tidak lulus }\end{array}$ & 4 \\
\hline
\end{tabular}

Berdasarkan analisis data hasil belajar peserta didik maka dapat dinyatakan bahwa game puzzle berbasis construct 2 dapat meningkatkan hasil belajar peserta didik. Terbukti dengan persentase ebih dari $85 \%$ peserta didik dikatakan lulus setelah penggunaan game puzzle berbasis construct 2 yaitu sebanyak $88 \%$ peserta didik dinyatakan mencapai nilai KKM 75 . Maka dapat dikatakan bahwa game puzzle berbasis construct 2 efektif diterapkan dalam proses pembelajaran karena dapat meningkatkan minat belajar, motivasi belajar dan hasil belajar peserta didik.

Berdasarkan tabel persentase minat belajar maka dapat dikatakan bahwa game puzzle berbasis construct 2 efektif digunakan dalam proses pembelajaran karena minat belajar peserta didik berada dalam kategori baik dengan persentase $61,76 \%$ $(61 \%-80 \%)$.

Tabel 12. Distribusi Frekuensi dan Kategori Nilai Motivasi Belajar Peserta Didik

\begin{tabular}{|c|c|c|c|c|c|}
\hline \multirow[b]{2}{*}{$\begin{array}{l}\text { Nila } \\
\text { i }\end{array}$} & \multirow{2}{*}{$\begin{array}{c}\text { Katego } \\
\text { ri }\end{array}$} & \multicolumn{2}{|c|}{ Frekuensi } & \multicolumn{2}{|c|}{ Persentase $(\%)$} \\
\hline & & $\begin{array}{c}\text { Sebelu } \\
\text { m }\end{array}$ & $\begin{array}{c}\text { Sesuda } \\
\mathrm{h}\end{array}$ & $\begin{array}{c}\text { Sebelu } \\
\text { m }\end{array}$ & $\begin{array}{c}\text { Sesuda } \\
\mathrm{h}\end{array}$ \\
\hline $\begin{array}{c}26 \\
- \\
45\end{array}$ & $\begin{array}{c}\text { Sangat } \\
\text { Renda } \\
\mathrm{h}\end{array}$ & 0 & 0 & 0 & 0 \\
\hline $\begin{array}{c}46 \\
- \\
65\end{array}$ & $\underset{\mathrm{h}}{\text { Renda }}$ & 13 & 0 & $\begin{array}{c}38,23 \\
\%\end{array}$ & 0 \\
\hline $\begin{array}{c}66 \\
- \\
85 \\
\end{array}$ & Cukup & 21 & 34 & $\begin{array}{c}61,76 \\
\%\end{array}$ & $100 \%$ \\
\hline $\begin{array}{c}86 \\
- \\
105 \\
\end{array}$ & Tinggi & 0 & 0 & 0 & 0 \\
\hline $\begin{array}{c}106 \\
- \\
125 \\
\end{array}$ & $\begin{array}{l}\text { Sangat } \\
\text { Tinggi }\end{array}$ & 0 & 0 & 0 & 0 \\
\hline
\end{tabular}

Berdasarkan tabel persentase motivasi belajar maka dapat dikatakan bahwa game puzzle berbasis construct 2 efektif digunakan dalam proses

\section{Kesimpulan}

Berdasarkan hasil peneltian dapat disimpulkan sebagai berikut.

1. Pengembangan media pembelajaran menggunakan model pengembangan 4D yang meliputi tahap define, design, develop dan disseminate.

2. Game puzzle berbasis construct 2 layak digunakan dalam proses pembelajaran karena berada dalam kategori "valid" baik dari media dan materi konsep sistem peredaran darah dengan nilai rata-rata kedua validator yaitu 4 .

3. Game puzzle berbasis construct 2 praktis digunakan dalam proses pembelajaran karena berada dalam kategori "praktis" baik dari respon guru dan

4. Game puzzle berbasis construct 2 efektif diterapakan dalam proses pembelajaran karena dapat meningkatkan minat dan motivasi belajar peserta didik. Setelah penggunaan game puzzle berbasis construct 2 dalam proses pembelajaran minat belajar peserta didik meningkat dari kategori cukup menjadi kategori tinggi atau memiliki minat belajar yang tinggi. Motivasi belajar peserta didik juga meningkat dari kategori tinggi menjadi kategori sangat tinggi yaitu memiliki motivasi belajar yang sangat baik. Game puzzle berbasis construct 2 efektif diterapkan dalam proses pembelajaran karena sebanyak $88 \%$ peserta didik yang mencapai nilai KKM. respon peserta didik. 


\section{Daftar Pustaka}

Amory, A \& Seagram, R. Educational Game Models: Conceptualization and Evaluation. South African Journal of Higher Education, 17 (2), 206-217. 2003.

Annisa, M. \& Marlina, L. Teaching Writing Descriptive Text by Using Crossword Puzzle for Second grade of Junior High School Students, 2 (2), 170-177. 2014.

Braghirolli, L.F,. et al. Benefits of educational games as an introductory activity in industrial engineering education. Computers in Human Behavior, 58, 315-324. 2016.

Daud, F. \& Rahmadana, A. Pengembangan media pembelakaran Biologi Berbasis E-Learning pada Materi Eksresi kelas XI IPA 3 SMAN 4 Makassar. Jurnal Bionature, 16 (1), 28-36. 2015.

Gunawan, F. Aplikasi Game Petualangan bagi AnakAnak sebagai Media Pembelajaran Flora dan Fauna di Indonesia. Jurnal Teknologi dan Informasi, 3 (1), 52-55. 2015.

Hisyam, Z. Strategi Pembelajaran Aktif. Yogyakarta: Insan Mandiri. 2008.

Husna, N., Sari, S, A., \& Halim, A. Pengembangan Media Puzzle Materi Pencemaran Lingkungan di SMP Negeri 4 Banda Aceh. Jurnal Pendidikan Sains Indonesia, 5 (1), 66-71. 2017.

Kurniawan, I., Tambunan, T.D., \& Sardi, I. L. Game Pembelajaran Matematika Untuk Anak SD Kelas 1 dan 2 Berbasis Android Menggunakan Construct 2, 1 (3), 2088-2094. 2015.

Liu, E.Z.F \& Chen, P.K. The Effect of Games Based Learning on Students Learning performance in Science Learning. Procedia, 103 (13), 1044-1051. 2013.

Lutviani, U. Pengembangan Puzzel sebagai Media Pembelajaran pada Materi Indonesia Masa Islam Kelas XII SMAN 3 Bojonegoro. Jurnal Pendidikan Sejarah, 4 (2), 344-357. 2016.

Riduwan. Metode \& Teknik Menyusun Tesis. Bandung: Alfabeta. 2010.

Riduwan. Dasar-Dasar Statistik. Bandung: Alfabeta. 2013.

Sudjono, A. Pengantar Statistik Pendidikan. Jakarta: Raja Grafindo. 2005.

Usman, U. 2003. Menjadi Guru Profesional. Bandung : PT Remaja Rosdakarya.

Yudasmara, G.A, \& Desi, P. 2005. Pengembangan Media Pembelajaran Interaktif Biologi untuk Meningkatkan Hasil Belajar Siswa SMP. Jurnal Pendidikan dan Pengajaran, 48 (1-3), 1-8. 2005. 